\title{
Synthesis and Characterization of Nanocrystalline A1-20 at. \% Cu Powders Produced by Mechanical Alloying
}

\author{
Molka Ben Makhlouf ${ }^{1}$, Tarek Bachaga ${ }^{1,2, *}$, Joan Josep Sunol ${ }^{2}$, Mohamed Dammak ${ }^{1}$ and \\ Mohamed Khitouni ${ }^{1}$ \\ 1 Laboratory of Inorganic Chemistry, University of Sfax, Sfax 3000, Tunisia; \\ molkabenmakhlouf@yahoo.fr (M.B.M.); meddammak@yahoo.fr (M.D.); khitouni@yahoo.fr (M.K.) \\ 2 Department de Fisica, Universitat de Girona, Campus Montilivi, Girona 17071, Spain; \\ joanjosep.sunyol@udg.edu \\ * Correspondence: bachagatarak@yahoo.fr; Tel.: +216-950-607-15 (ext. 00216); Fax: +216-742-744-37 \\ Academic Editor: Nong Gao \\ Received: 8 May 2016; Accepted: 15 June 2016; Published: 29 June 2016
}

\begin{abstract}
Mechanical alloying is a powder processing technique used to process materials farther from equilibrium state. This technique is mainly used to process difficult-to-alloy materials in which the solid solubility is limited and to process materials where nonequilibrium phases cannot be produced at room temperature through conventional processing techniques. This work deals with the microstructural properties of the Al-20 at. \% Cu alloy prepared by high-energy ball milling of elemental aluminum and copper powders. The ball milling of powders was carried out in a planetary mill in order to obtain a nanostructured Al-20 at. \% Cu alloy. The obtained powders were characterized using scanning electron microscopy (SEM), differential scanning calorimetry (DSC) and X-ray diffraction (XRD). The structural modifications at different stages of the ball milling are investigated with X-ray diffraction. Several microstructure parameters such as the crystallite sizes, microstrains and lattice parameters are determined.
\end{abstract}

Keywords: mechanical alloying; nanocrystalline; crystallite sizes; morphology

\section{Introduction}

Mechanical alloying (MA) is considered a powerful technique as it can facilitate true alloying materials. In general, both stable and metastable phases can be produced by ball milling [1-6]. Solid-state reactions induced by high-energy ball milling have recently attracted a large amount of research work $[7,8]$. This is because the high-energy ball milling approach has been recognized as a complex process which can be applied to the processing of advanced materials at low cost. Among these, mechanical alloying (MA) has often been reported to be a powerful and relatively simple technique that allows for the preparation of nanostructured alloys [8]. It is commonly known that during MA, powders undergo a severe plastic deformation, which introduces a number of defects into the material, and it is worth noting that this causes a gradual change in the state of the powder mixtures and hence their properties [8,9]. Further, Eckert et al. [10] found that the final grain size is determined by the competition between the deformation produced by a milling process, and the dynamic recovery in the milled material. On the other hand, it has been suggested that the stacking fault energy (SFE) has a strong influence on the evolution of the dislocation structure, which precedes and results in the nanocrystalline structure formation [11].

The Al-Cu system is an example of a binary system with a low solid miscibility at room temperature (a miscibility of approximately 0.1 at. \% [12]). According to the phase diagram, the solubility of $\mathrm{Cu}$ in $\mathrm{Al}$ is about 1 at. $\%$ near $350{ }^{\circ} \mathrm{C}$ and reaches a maximal value (about 2.5 at. \%) at $548^{\circ} \mathrm{C}$ [13]. However, by means 
of MA, Al-Cu solid solutions can be obtained. At these temperatures, the solid solution is in equilibrium with the chemical compound $\mathrm{Al}_{2} \mathrm{Cu}$. In general, the mechanical strengthening of $\mathrm{Al}$ metal was usually achieved by the impurity doping of $0.5 \%-4 \% \mathrm{Cu}[14,15]$. Further studies on $\mathrm{Al}-\mathrm{Cu}$ have reported that $\theta-\mathrm{Al}_{2} \mathrm{Cu}$ is the first nucleus intermetallic compound [16]. Premkumar et al. [15] added that this intermetallic becomes $\gamma-\mathrm{Al}_{4} \mathrm{Cu}_{9}$ or $\eta-\mathrm{AlCu}$ as the purity of the $\mathrm{Cu}$ wire increases. Generally, depending on the thermodynamics, the diffusion couples of $\mathrm{Al}-\mathrm{Cu}$ can be produced in several intermediate phases and in many ways. Earlier studies reported by Li et al. [17] and by Chattopadhyay [18] have indicated that mechanical alloying yields a metastable bcc solid solution in the composition range of Al-35 to 65 at. \% Cu. Moreover, Murray indicated that the maximum solid solubility of copper in $\mathrm{Al}$ by mechanical alloying is estimated to be 2.7 at. \% Cu, which is larger than the solubility of 0.1 at. \% Cu in the equilibrium state at room temperature. In the present work, we are interested the compound $\mathrm{Al}-20$ at. \% Cu prepared by the mechanical milling technique. The microstructure changes as a function of milling time were investigated by means of $X$-ray diffraction $(X R D)$ and scanning electron microscopy (SEM). Furthermore, special attention will be paid to thermal stability by using differential scanning calorimetry (DSC).

\section{Materials and Methods}

$\mathrm{Al}(99.5 \%$ purity, mean particle size $<50 \mu \mathrm{m}, 325$ mesh) and $\mathrm{Cu}$ (99.95\% purity, mean particle size $<40 \mu \mathrm{m}, 200 \mathrm{mesh}$ ) elemental powders were used as starting materials. The initial powders with the nominal compositions of $\mathrm{Al}-20$ at. $\% \mathrm{Cu}$ were milled up to $20 \mathrm{~h}$ using a planetary ball mill (Pulverisette P7, Fritsch, Industriestraße 8, Idar-Oberstein, Germany) under argon atmosphere. The ball-to-powder weight ratio was maintained as 1:5. The milling was repeated for different milling times $(2 \mathrm{~h}, 4 \mathrm{~h}, 6 \mathrm{~h}$, $10 \mathrm{~h}, 16 \mathrm{~h}$, and $20 \mathrm{~h}$ ) at $600 \mathrm{rpm}$. To avoid the local temperature rise inside the vials during milling, each $10 \mathrm{~min}$ of milling was followed by a pause of $5 \mathrm{~min}$. The structural changes of the milled samples were investigated by X-ray diffraction (XRD) by means of a Bruker D8 Advance diffractometer (Bruker

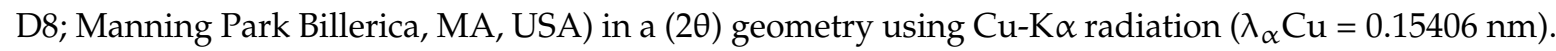
The XRD data was collected at a slow scan rate of $0.016^{\circ} / 4 \mathrm{~s}$. The microstructural parameters were taken out from the refinement of the XRD patterns by using the MAUD program [19] which is based on the Rietveld method. The evolution of the particle morphology during MA was carried out by means of a scanning electron microscope (SEM) (DSM960A ZEISS, Norman, OK, USA) with energy dispersive X-ray microanalysis (EDX, Norman, OK, USA). Thermal analyses were performed by means of differential scanning calorimetry (DSC, DSC822 apparatus of Mettler Toledo; Columbus, OH, USA) instrument with a heating rate of $20^{\circ} \mathrm{C} / \mathrm{min}$ up to $700^{\circ} \mathrm{C}$ under constant $\mathrm{Ar}$ flow.

\section{Results and Discussion}

\subsection{X-ray Diffraction}

Evidence of the continuous refinement of the microstructure and the introduction of several structural defects (grain boundaries, dislocations, vacancies, stacking faults, etc.), with increasing milling time, was provided by the decrease of the diffraction peak intensities and their broadening. The disappearance and / or the appearance of some peaks can be assigned to the mixing of the elemental powders and, therefore, to the formation of new phases [8].

Figure 1 presents the XRD patterns of the powders milled for various milling times. The unmilled sample exhibits a pattern consistent with the structure of fcc-Al (space group Fm3m; $a_{0}=0.4046(4) \mathrm{nm}$ ) and fcc-Cu (space group Fm3m; $a_{0}=0.3611(4) \mathrm{nm}$ ) precursors. As shown in Figure 1, after $2 \mathrm{~h}$ milling, the peaks specific to the $\mathrm{Al}$ and $\mathrm{Cu}$ diffraction peak profiles became asymmetric and started to broaden and no significant mechano-reaction occurred during this initial period of milling. However, after $4 \mathrm{~h}$ milling, one can see the decrease of the main $\mathrm{Cu}$ diffraction peak and the appearance of new ones for $2 \theta \sim 43.98 ; 64.14 ; 80.96$ and $97.40^{\circ}$. These peaks can be indexed as nonequilibrium body-centered cubic (bcc) phase with space group Immm and lattice parameters $a_{0}=0.2897(4) \mathrm{nm}$. The same results have been found by Chattopadhyay et al. [5] after MA of the Al-Cu system in the composition range 
$\mathrm{Al}_{65} \mathrm{Cu}_{35}$ to $\mathrm{Al}_{35} \mathrm{Cu}_{65}$. After $6 \mathrm{~h}$ milling, tetragonal- $\mathrm{Al}_{2} \mathrm{Cu}$ with space group $\mathrm{I} 4 / \mathrm{mcm}$ and lattice parameters $a=0.9107(4) \mathrm{nm}$ and $c=0.4460(4) \mathrm{nm}$ started to form.

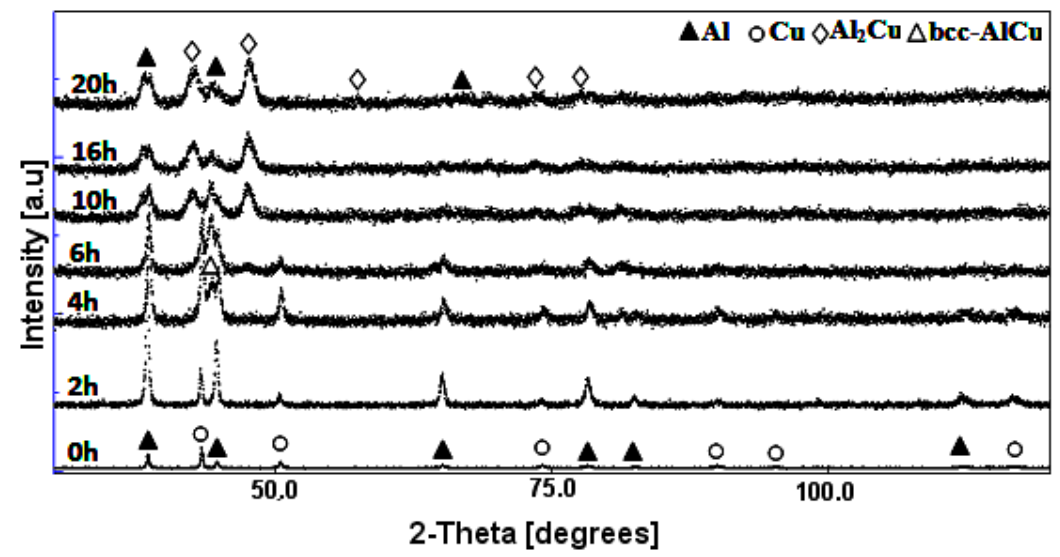

Figure 1. XRD patterns of Al-20 at. \% Cu powders collected at different milling times.

Figure 2 gives the Rietveld refinement for patterns obtained before (corresponds to $0 \mathrm{~h}$ ) and after mechanical milling for $4 \mathrm{~h}, 6 \mathrm{~h}$, and $20 \mathrm{~h}$. The best Rietveld refinement $(\mathrm{GOF}=1.12)$ for the pattern of the unmilled powder is obtained with two crystalline phases as well as the fcc-Al phase with the lattice parameter $a=0.4051(1) \mathrm{nm}$ and the fcc-Cu phase with the lattice parameter $a=0.3617(5) \mathrm{nm}$ (Figure $2 \mathrm{a})$. The best Rietveld refinement $(\mathrm{GOF}=1.3)$ for the pattern of the mixture milled for $4 \mathrm{~h}$ is obtained with both crystalline phases and the apparition of a bcc-AlCu solid solution with the lattice parameter $a=0.2897(4) \mathrm{nm}$ (Figure $2 \mathrm{~b}$ ). Increasing the milling time up to $6 \mathrm{~h}$, the diffusion of the $\mathrm{Cu}$ atoms into the $\mathrm{Al}$ matrix leads to the formation of two supersaturated solid solutions, tetragonal- $\mathrm{Al}_{2} \mathrm{Cu}$ and bcc-AlCu. This result was confirmed by the best Rietveld refinement (GOF $=1.27$ ) of the pattern corresponding to MA powder for $6 \mathrm{~h}$ (Figure 2c). In a previous work, Onuki et al. [20] reported that the formation of the tetragonal- $\mathrm{Al}_{2} \mathrm{Cu}$ phase during mechanical milling is due to the negative enthalpy of the mixing of the Al-Cu system. Furthermore, the solubility of the solutes is enhanced with a grain refinement on the nanometer scale. After $20 \mathrm{~h}$ milling, the Rietveld refinement of the powder pattern was successfully obtained with the fcc-Al and tetragonal- $\mathrm{Al}_{2} \mathrm{Cu}$ phases (Figure $2 \mathrm{~d}$ ). These phases correspond to the Al-20 at. \% Cu composition in the equilibrium phase diagram of the Al-Cu system at room temperature.
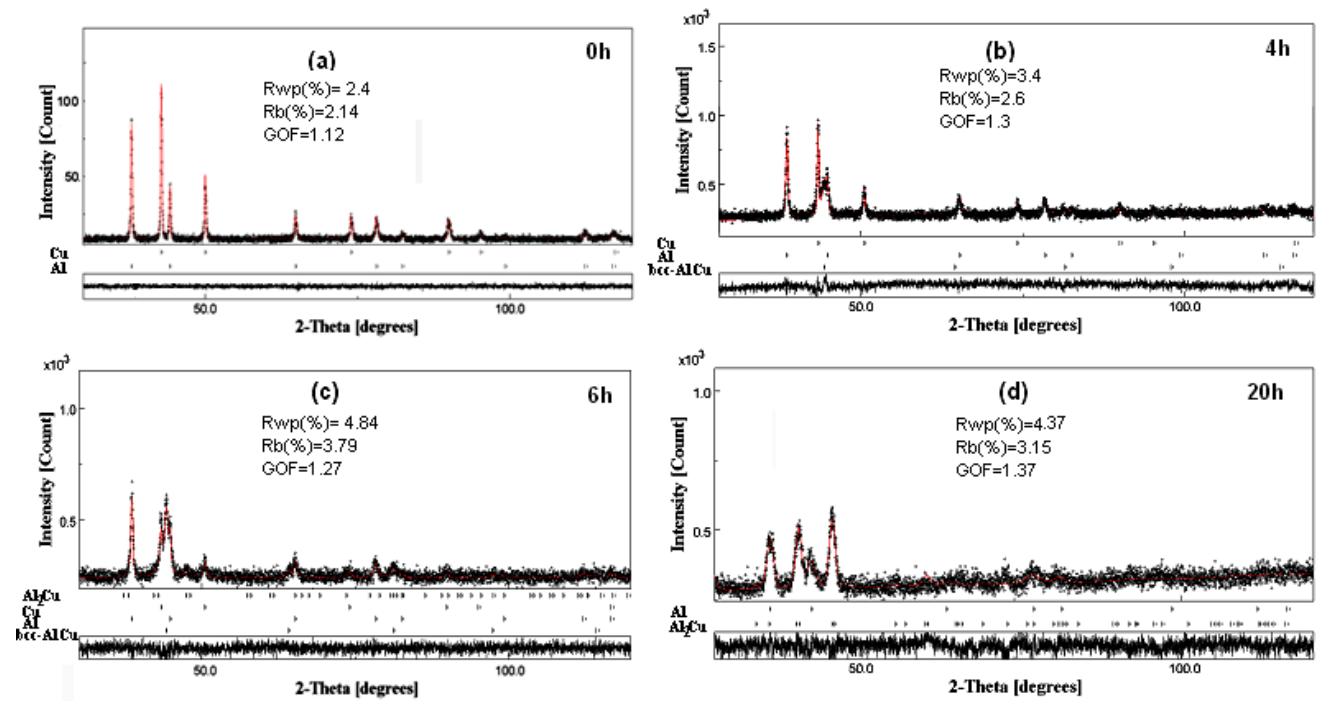

Figure 2. Rietveld refinement of the XRD patterns of the $\mathrm{Al}-20$ at. $\% \mathrm{Cu}$ powders at different milling times: (a) $0 \mathrm{~h}$; (b) $4 \mathrm{~h}$; (c) $6 \mathrm{~h}$; (d) $20 \mathrm{~h}$. 
The lattice parameter of $\mathrm{Cu}$ increases from $0.3611(4)$ to $0.3617(5) \mathrm{nm}$ after $2 \mathrm{~h}$ of milling. The relative deviation of the lattice parameter from that of the perfect crystal, which is defined by $\Delta a / a_{0}=\left(a-a_{0}\right) / a_{0}$, reaches as much as $0.16 \%$. The lattice parameter of the $\mathrm{Al}$ phase is enhanced by $0.20 \%$ after $4 \mathrm{~h}$ of milling. Sui et al. [21] attributed this lattice distortion (lattice expansion or contraction) to the supersaturation of point defects or vacancies inside the nanometer crystallites due to their higher energetic solution.

The observed broadening of diffraction peaks suggests the accumulation of lattice strain and a reduction in crystallite size. Figure 3 presents the evolutions of the average crystallite size and microstrains deduced from the Rietveld refinement as a function of milling time. As shown, one can observe an important decrease of the crystallite size and an increase of the microstrains during the first stage of milling ( 0 to $4 \mathrm{~h}$ milling). For a prolonged milling time, both the crystallite size and microstrains become less dependent on the milling time. After $10 \mathrm{~h}$ of milling, the bcc-AlCu is characterized by a smaller crystallite size and higher microstrains as compared to the $\mathrm{Al}_{2} \mathrm{Cu}$. The final values of the average crystallite size of the $\mathrm{Al}$ and $\mathrm{Al}_{2} \mathrm{Cu}$ phases calculated after $20 \mathrm{~h}$ of milling were $7 \mathrm{~nm}$ and $13 \mathrm{~nm}$, respectively. The high degree of microstrains in the $\mathrm{Al}_{2} \mathrm{Cu}(1.08 \%)$ may be due to a high concentration of stacking faults and a high dislocation density. In general, microstrains may arise from a mismatch in the size of the constituents, an increase in the grain boundary fraction, or a mechanical deformation [22]. The microstrains caused by MA have also been previously reported in the literature and have commonly been attributed to the generation and movement of dislocations [23,24]. In order to investigate the stage's mechanical stabilities during milling, we have the calculated phase's proportions of the identified phase as a function of the milling times. Note that there are some phases that progressively decrease ( $\mathrm{Al}$ and $\mathrm{Cu}$ ) and others which arise in the form of solid solutions (bcc-AlCu and $\mathrm{Al}_{2} \mathrm{Cu}$ ). In addition, we observe that the percentage of the bcc-AlCu stage reaches a maximum $(70 \%)$ after $12 \mathrm{~h}$ of milling, and then it progressively decreases to a value of $8.80 \%$ after $16 \mathrm{~h}$ of milling, while the percentage of the $\mathrm{Al}_{2} \mathrm{Cu}$ phase increases continuously with the milling time to reach its maximum value at a milling time of $20 \mathrm{~h} \mathrm{(82 \% ).} \mathrm{So} \mathrm{the} \mathrm{final} \mathrm{system} \mathrm{obtained} \mathrm{after} 20 \mathrm{~h}$ of milling is biphasic with two phases: fcc- $\mathrm{Al}$ and tetragonal- $\mathrm{Al}_{2} \mathrm{Cu}$ phases.

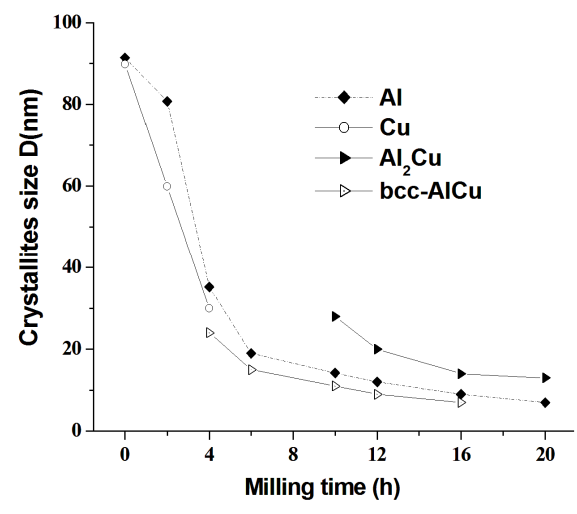

(a)

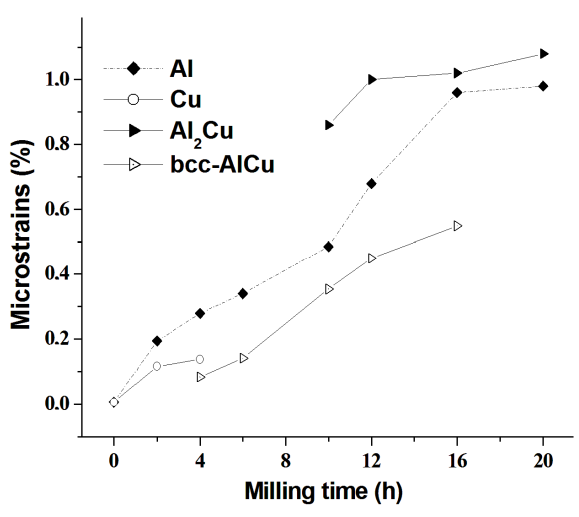

(b)

Figure 3. Dependences of refined microstructural parameters of Al-20 at. \% Cu powder mixtures on milling time: (a) Crystallite size and (b) Microstrains.

\subsection{Scanning Electron Microscopy}

The morphologies of as-received $\mathrm{Al}$ and $\mathrm{Cu}$ powders are shown in Figure 4. Before milling, the Al particles have a spherical-like morphology while the $\mathrm{Cu}$ particles have elongated forms (Figure 4a). The changes in morphology during the milling process are due to the competition between the fracturing, cold welding, agglomeration and de-agglomeration of the powder particles. After $4 \mathrm{~h}$ of milling, as is normal during the milling of ductile-ductile systems, the mixture is only composed of big particles (Figure $4 \mathrm{~b}$ ). Since the powder particles are soft during the early stage of milling, they tend to 
weld together and form big particles. With the increase of the milling time $(6 \mathrm{~h})$, fine particles aggregate to shape flake-like powders. A broad range of a particle size can then be seen (Figure 4c). Due to the hardening of the powder under the effect of the repeated shocks of the balls during continued milling $(20 \mathrm{~h})$, the particles become fractured, and are hence fine and fairly homogeneous in size and shape (Figure $4 \mathrm{~d}$ ). The induced heavy plastic deformation in the powder particles during the milling process gives rise to the creation of a great amount of crystal defects such as dislocations, vacancies, interstitials and grain boundaries which promote a solid-state reaction at ambient temperature. Depending on the initial mixture, changes in structures of mechanically alloyed powders can occur as follows: grain refinement, solid solution diffusion and/or formation of new phases.

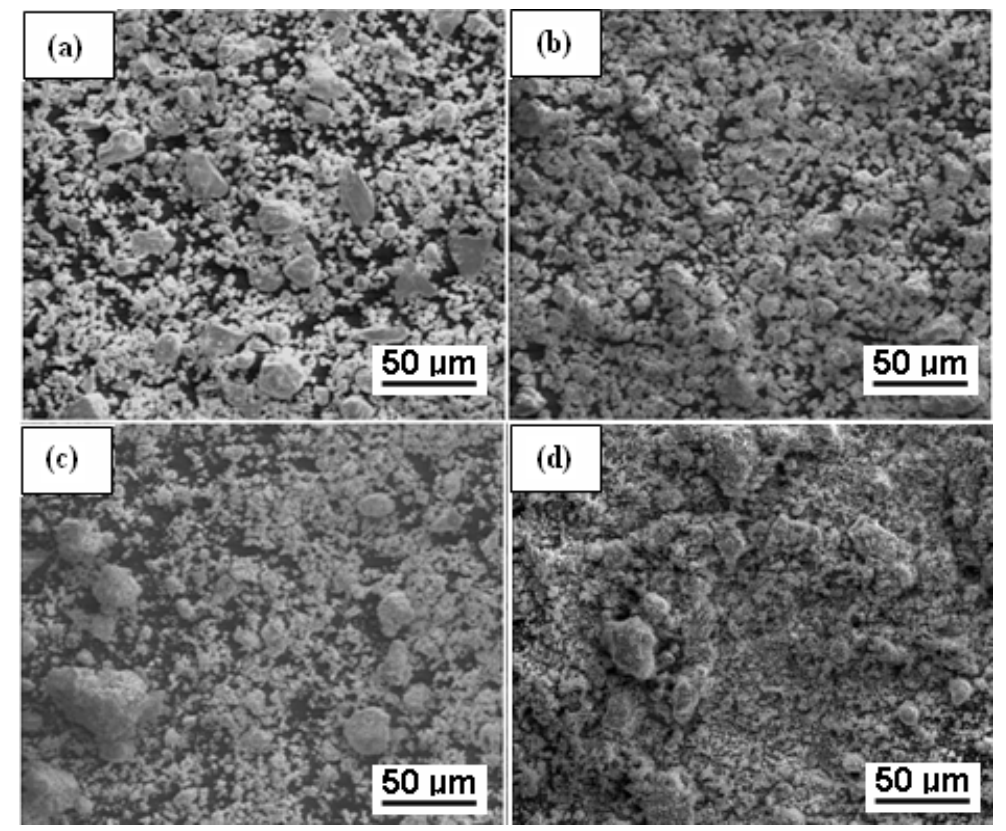

Figure 4. SEM morphologies of the Al-20 at. \% Cu powders for different milling times: (a) 0 h; (b) 4 h; (c) $6 \mathrm{~h}$; (d) $20 \mathrm{~h}$.

\subsection{Thermal Stability}

Nanostructured and disordered structures obtained by MA are metastable and, therefore, they will experience an ordering transition during heating. Hence, the thermal stability of the alloy is dependent on the structural state after each milling time. Several thermal effects are revealed in the DSC curves of the Al-20 at. \% Cu powders milled several times (Figure 5). Before milling, the analysis of the mixture of the powders in the temperature range $25^{\circ} \mathrm{C}-700{ }^{\circ} \mathrm{C}$ shows an endothermic peak at $660{ }^{\circ} \mathrm{C}$, attributed to the melting of aluminum particles [25]. As shown in Figure 5b, the DSC trace of $4 \mathrm{~h}$ milled powder exhibited an endothermic peak at $560{ }^{\circ} \mathrm{C}$ followed by an exothermic peak at $580^{\circ} \mathrm{C}$. This later was followed by a small endothermic peak at $610{ }^{\circ} \mathrm{C}$. The endothermic peaks might be caused by the melting of the bcc-AlCu phase identified by XRD (see Figure 1) and another fine Al-rich phase formed through the diffusion of $\mathrm{Cu}$ into Al during heating. After the powder was milled for $6 \mathrm{~h}$, the DSC trace presented an exothermic peak at $580{ }^{\circ} \mathrm{C}$ followed by an endothermic peak at $650{ }^{\circ} \mathrm{C}$, which might be related to the formation and dissolution of the Al-rich phase. The same results have been reported by Ying et al. [26] in the case of $\mathrm{Cu}-\mathrm{Al}$ alloy with an $\mathrm{Al}$ composition of 35 at. \% for different times. They attributed these endothermic peaks to the melting of Al-rich phases formed during heating. The endothermic peaks identified for the powder milled for $12 \mathrm{~h}$ were in the temperature range of $560{ }^{\circ} \mathrm{C}$ and $580^{\circ} \mathrm{C}$, and they were likely caused by the melting of $\mathrm{Al}$-rich phases initially formed through the diffusion of $\mathrm{Cu}$ into $\mathrm{Al}$ during $\mathrm{MA}$ as well as bcc- $\mathrm{AlCu}$ and $\mathrm{Al}_{2} \mathrm{Cu}$. The DSC trace of the powders milled for $20 \mathrm{~h}$ exhibited an endothermic peak at $550{ }^{\circ} \mathrm{C}$ followed by 
an exothermic one at $600{ }^{\circ} \mathrm{C}$, attributed to the melting of the eutectic Al-Cu binary phase and the formation of the $\mathrm{Al}-\mathrm{Cu}$ intermetallic, respectively.

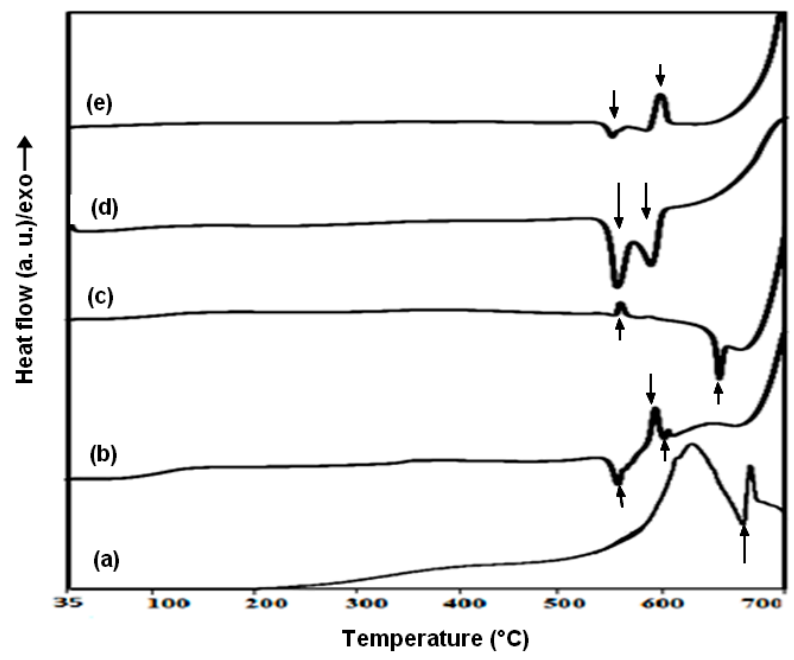

Figure 5. DSC pattern of the Al-20 at. \% Cu powders milled for different milling times: (a) $0 \mathrm{~h}$; (b) $4 \mathrm{~h}$; (c) $6 \mathrm{~h} ;(\mathbf{d}) 16 \mathrm{~h} ;(\mathbf{e}) 20 \mathrm{~h}$.

\section{Conclusions}

Structural, morphological and thermal properties of mechanically alloyed Al-20 at. \% Cu powders have been carefully studied as a function of milling time. The interdiffusion of $\mathrm{Cu}$ and $\mathrm{Al}$ leads to the formation of bcc-AlCu and tetragonal $\mathrm{Al}_{2} \mathrm{Cu}$ phases. The formation of the bcc-AlCu phase was observed in the early stage of milling ( $4 \mathrm{~h}$ of milling), while the tetragonal $\mathrm{Al}_{2} \mathrm{Cu}$ was revealed from $6 \mathrm{~h}$ of milling. It was also found that the crystallite size of the relatively milled powder was decreased with the increasing milling duration. The crystallite size and microstrain of the milled powder were estimated to be in the range of $10-15 \mathrm{~nm}$ and $1 \%-1.1 \%$, respectively. It was shown that during the milling process, $\mathrm{Al}$ and $\mathrm{Cu}$ particles underwent severe plastic deformation, which can lead to grain refinement, solid solution diffusion and/or the formation of new phases. The thermal stability of the mechanically alloyed Al-20 at. \% Cu powders was found to be dependent on the structural state after each milling time. Endothermic and exothermic reactions are revealed in the DSC curves; they are attributed to the melting and the formation of Al-rich phases.

Acknowledgments: Authors would like to thank Xavier Fontrodona Gubau for her XRD support and Leila Mahfoudhi from the English Language Unit at the Faculty of Sciences of Sfax (Tunisia) for accepting to proofread and polish the language of this paper.

Author Contributions: Joan Joseph Sunol, Mohamed Dammak and Mohamed Khitouni conceived, designed the experiments and wrote the SEM, DSC and XRD results; Molka Ben Makhlouf and Tarek Bachaga performed the experiments and analyzed the data. All authors discussed the results and worked on preparing the manuscript.

Conflicts of Interest: The authors declare no conflict of interest.

\section{References}

1. Bachaga, T.; Daly, R.; Escoda, L.; Suñol, J.J.; Khitouni, M. Amorphization of $\mathrm{Al}_{50}\left(\mathrm{Fe}_{2} \mathrm{~B}\right)_{30} \mathrm{Nb}_{20}$ mixture by mechanical alloying. J. Metall. Mater. Trans. A 2013, 44, 4718-4724. [CrossRef]

2. Esparza, R.; Rosas, G.; Ascencio, J.A.; Pérez, R. Effects of minor element additions to the nanocrystalline FeAl intermetallic alloy obtained by mechanical alloying. Mater. Manuf. Process. 2005, 20, 823-832. [CrossRef]

3. Sharma, P.; Sharma, S.; Khanduja, D. On the use of ball milling for the production of ceramic powders. Mater. Manuf. Process. 2015, 30, 1370-1376. [CrossRef] 
4. Chittineni, K.; Bhat, D.G. X-ray Diffraction investigation of the formation of nanostructured metastable phases during short-duration mechanical alloying of $\mathrm{Cu}-\mathrm{Al}$ powder mixtures. Mater. Manuf. Process. 2006, 21, 527-533. [CrossRef]

5. Chattopadhyay, P.P.; Mann, I. Effect of Partial Substitution of $\mathrm{Cu}$ in $\mathrm{Al}_{65} \mathrm{Cu}_{35}$ by Transition Metal in Mechanical Alloying of $\mathrm{Al}_{65} \mathrm{Cu}_{20} \mathrm{TM}_{15}$. Mater. Manuf. Process. 2002, 17, 583-594. [CrossRef]

6. Qiu, Y.; Gu, M.L.; Zhang, F.G.; Wei, Z. Influence of Tool Inclination on Micro-Ball-End Milling of Quartz Glass. Mater. Manuf. Process. 2014, 29, 1436-1440. [CrossRef]

7. Archana, M.S.; Ramakrishna, M.; Ravi, C.; Gundakaram, V.V.; Srikanth, S.S.; Joshi, S.V. Nanocrystalline Phases during Mechanically Activated Processing of an Iron (Fe)-Aluminium(40 at.\% Al) Alloy. Mater. Manuf. Process. 2014. [CrossRef]

8. Suryanarayana, C. Mechanical alloying and milling. Prog. Mater. Sci. 2001, 46, 1-184. [CrossRef]

9. Qingquan, K.; Lian, L.; Liu, Y.; Zhang, J. Fabrication and Characterization of Nanocrystalline Al-Cu Alloy by Spark Plasma Sintering. Mater. Manuf. Process. 2014, 29, 1232-1236.

10. Eckert, J.; Holzer, J.C.; Krill, C.E.; Johnson, W.L. Mechanically driven alloying and grain size changes in Non crystalline Fe-Cu powders. J. Appl. Phys. 1993, 73, 2794-2802. [CrossRef]

11. Slimi, M.; Azabou, M.; Escoda, L.; Suñol, J.J.; Khitouni, M. Stacking faults and structural characterization of mechanically alloyed $\mathrm{Ni}_{50} \mathrm{Cu}_{10}\left(\mathrm{Fe}_{2} \mathrm{~B}\right)_{10} \mathrm{P}_{30}$ powders. Eur. Phys. J. Plus 2015, 130, 1-8. [CrossRef]

12. Murray, J.L. The aluminium-copper system. Int. Met. Rev. 1985, 30, 211-233. [CrossRef]

13. Massalski, T.B.; Okamoto, H.; Subramanian, P.R.; Kacprzak, L. Binary Alloy Phase Diagrams, 2nd ed.; ASM International: Novelty, OH, USA, 1990.

14. Nguyen, L.T.; McDonald, D.; Danker, A.R.; Ng, P. Optimization of copper wire bonding on Al-Cu metallization. IEEE Trans. Compon. Packag. Manuf. Technol. A 1995, 18, 423-429. [CrossRef]

15. Premkumar, J.; Kumar, B.S.; Madhu, M.; Sivakumar, M.; Song, K.Y.J.; Wong, Y.M. Key factors in Cu wire bonding reliability: Remnant aluminum and $\mathrm{Cu} / \mathrm{Al}$ IMC thickness. In Proceedings of the 10th Electronics Packaging Technology Conference, Singapore, 9-12 December 2008.

16. Xu, H.; Liu, C.; Silberschmidt, V.V.; Chen, Z. A re-examination of the mechanism of thermosonic copper ball bonding on aluminium metallization pads. Scr. Mater. 2009, 61, 165-168. [CrossRef]

17. Li, F.; Ishihara, K.N.; Singu, P.H. The Formation of Metastable Phases by Mechanical Alloying in the Aluminum and Copper System. Metall. Trans. A 1991, 22, 2849-2854. [CrossRef]

18. Chattopadhyay, P.P. Ph.D. Thesis, Indian Institute of Technology, Kharagpur, India, 2000.

19. Lutterotti, L. MAUD, Int. Union of Crystallography CPD Newsletter (IUCr), No. 24. 2000.

20. Onuki, J.; Koizumi, M. Investigation of the Reliability of Copper Ball Bonds to Aluminum Electrodes. IEEE Trans. Compon. Hybrids Manuf. Technol. 1987, 12, 550-555. [CrossRef]

21. Sui, M.L.; Lu, K. Variation in lattice parameters with grain size of a nanophase Ni-3P compound. Mater. Sci. Eng. A 1994, 541, 179-180.

22. Eckert, J.; Holzer, J.C.; Johnson, W.L. Thermal stability and grain growth behavior of mechanically alloyed nanocrystalline Fe-Cu alloys. J. Appl. Phys. 1993, 73, 131-141. [CrossRef]

23. Mohamed, F.A. A dislocation model for the minimum grain size obtainable by milling. Acta Mater. 2003, 51, 4107-4119. [CrossRef]

24. Kalita, M.P.C.; Perumal, A.; Srinivasan, A. Structure and magnetic properties of nanocrystalline $\mathrm{Fe}_{75} \mathrm{Si}_{25}$ powders prepared by mechanical alloying. J. Magn. Magn. Mater. 2000, 320, 2780-2783. [CrossRef]

25. Das, S.; Peperezko, J.; Wu, R.; Wilde, G. Under cooling and glass formation in Al-based alloys. Mater. Sci. Eng. A 2001, 159, 304-306.

26. Ying, D.Y.; Zhang, D.L. Solid-state reactions between $\mathrm{Cu}$ and $\mathrm{Al}$ during mechanical alloying and heat treatment. J. Alloy. Compd. 2000, 311, 275-282. [CrossRef]

(C) 2016 by the authors; licensee MDPI, Basel, Switzerland. This article is an open access article distributed under the terms and conditions of the Creative Commons Attribution (CC-BY) license (http://creativecommons.org/licenses/by/4.0/). 